\title{
Análise fundamentalista de cooperativas agrícolas do interior do Rio Grande do Sul
}

\author{
Fundamentalist analysis of agricultural cooperatives of the interior of Rio Grande do Sul
}

\begin{abstract}
Resumo
O estudo objetivou analisar o desempenho econômico-financeiro de duas cooperativas agrícolas e identificar os fatores ambientais e mercadológicos que influenciaram nesses resultados. Os dados foram extraídos das demonstrações contábeis de 1997 a 2016, entrevistas semiestruturada com seus gestores e de informações disponibilizadas em páginas eletrônicas de Internet para os fatores ambientais e mercadológicos. Utilizou-se de abordagem quantitativa para obtenção dos índices, dos fatores ambientais e para a análise de correlação. Procedeu-se análise qualitativa nos resultados das entrevistas e para a classificação dos anos de crises e chuvas. Os resultados mostram que as cooperativas tiveram desempenho econômico-financeiro distintos, estando a cooperativa B em um cenário mais confortável do que a cooperativa A. Pela análise de correlação se percebeu menor correlação entre as contas da cooperativa A. Não foram identificadas correlações entre os fatores ambientais e mercadológicos com os resultados econômico-financeiros apresentados pelas cooperativas, significando que esses resultados representam o meio interno.
\end{abstract}

Palavras-chave: cooperativas, desempenho econômico-financeiro, indicadores, fatores externos

\begin{abstract}
The study aimed to analyze the economic and financial performance of two agricultural cooperatives and identify the environmental and market factors that influenced these results. Data were extracted from the financial statements from 1997 to 2016, semi-structured interviews with their managers and information made available on Internet websites for environmental and marketing factors. A quantitative approach was used to obtain indices, environmental factors and correlation analysis. Qualitative analysis was performed on the interview results and for the classification of the years of crises and rains. The results show that the cooperatives had different economic and financial performance, being the cooperative B in a more comfortable scenario than the cooperative A. The correlation analysis showed a lower correlation between the cooperative A accounts. No correlations were identified between the factors. environmental and marketing results with the economic and financial results presented by the cooperatives, meaning that these results represent the internal environment..
\end{abstract}

Keywords: cooperatives, economic and financial performance, indicators, external factors

Darlan Kohl Bronstrup'; Régis Friedrich ${ }^{\mathrm{II}}$; Rosane Maria Seibert ${ }^{\mathrm{III}}$; Raiziane Cássia Freire da Silva ${ }^{\mathrm{IV}}$; Luciana Moro de Souza ${ }^{\mathrm{V}}$

I Universidade Regional Integrada do Alto Uruguai e das Missões - URI - Campus Santo Ângelo. Santo Ângelo, RS darlankohl@outlook.com.

II Universidade Regional Integrada do Alto Uruguai e das Missões - URI - Campus Santo Ângelo. Santo Ângelo, RS regisfriedrich7@gmail.com.

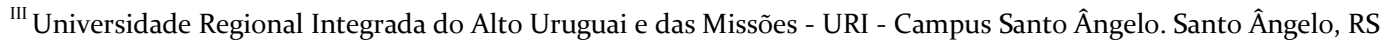
rseibert@san.uri.br.

${ }^{\text {IV }}$ Universidade Regional Integrada do Alto Uruguai e das Missões - URI - Campus Santo Ângelo. Santo Ângelo, RS raifreire@hotmail.com.

${ }^{\mathrm{V}}$ Universidade Regional Integrada do Alto Uruguai e das Missões - URI - Campus Santo Ângelo. Santo Ângelo, RS luciana@san.uri.br. 


\section{Introdução}

Cooperativas são organizações de pessoas com interesses comuns, geridas de maneira democrática e participativa (THE INTERNATIONAL CO-OPERATIVE ALLIANCE [ICA], s. d.). O cooperativismo é um movimento que tem se destacado no plano econômico mundial (MARTINS;

LUCATO, 2018) por ser visto como alternativa para promover o desenvolvimento socioeconômico da sociedade onde a cooperativa está inserida, devido à geração e a repartição de renda e à criação de empregos oportunizada por ela (SEBRAE, 2014). Por esse motivo, anseia-se que essas organizações disponham de saúde financeira para manter sua longevidade (SHAMSUDDIN; ISMAIL; MAHMOOD; ABDULLAH, 2017).

As cooperativas possuem peculiaridades que as diferem dos outros tipos de organizações sem fins lucrativos, mas que instigam a adoção de práticas que melhorem sua complexa gestão para enfrentar problemas como a assimetria de informações, além daqueles derivados da oscilação e da competitividade do mercado (MACIEL; SEIBERT; SILVA; WBATUBA; SALLA, 2018; MARTINS; LUCATO, 2018; SHAMSUDDIN et al., 2017). Nesse sentindo, destaca-se a importância do contínuo acompanhamento do ambiente e do mercado, bem como do desempenho econômico-financeiro, para que essas informações possibilitem melhores tomadas de decisões nas cooperativas, assim como, reduzam a assimetria da informação entre gestores, cooperados e demais partes interessadas (SHAMSUDDIN et al., 2017). Além disso, os índices econômico-financeiros fornecem informações que permitem antever situações de declínio no desempenho da organização (GIMENES; URIBEOPAZO, 2001).

Nesse contexto, este estudo buscou analisar o desempenho econômico-financeiro de duas cooperativas agrícolas, no período de 1997 a 2016, e identificar os fatores ambientais e mercadológicos que influenciaram nesses resultados. Destaca-se a relevância de analisar o desempenho econômico-financeiro das cooperativas, por meio de índices financeiros tradicionais atrelados as informações sociais da organização devido seu objetivo social (BIALOSKORSKI NETO; NAGANO; MORAES, 2006). O estudo de Martins e Lucato (2018) demonstrou que os índices econômico-financeiros tradicionais ainda são os mais utilizados na literatura empírica para analisar o desempenho das cooperativas e, portanto, assim também se fez no presente estudo, juntamente com fatores externos, representativos do ambiente e do mercado em que essas cooperativas estão inseridas, para analisar o desempenho das cooperativas alvo do estudo.

Os índices econômico-financeiros foram calculados a partir das demonstrações contábeis de duas cooperativas agrícolas, denominadas doravante, de A e B. Com este estudo buscou-se compreender os motivos pelos quais cooperativas com atividades similares, apresentam-se em situações econômicas e financeiras distintas, onde umas se sobressaem, como a cooperativa B e outras são insustentáveis, como a cooperativa A. Além disso, se constatou que os fatores ambientais e mercadológicos não influenciaram os resultados econômicos e financeiros das cooperativas. Esses resultados indicam a relevância da gestão das cooperativas na condução para a sustentabilidade. Assim, entende-se que este estudo contribui para o avanço do conhecimento sobre as cooperativas agrícolas, bem como, com a gestão das cooperativas por demonstrar os efeitos da tomada de decisão interna nos resultados econômicos e financeiros.

Devido a limitação do estudo aos resultados econômico-financeiros dessas duas cooperativas, sugere-se outras pesquisas comparativas com maior número de cooperativas, de outros segmentos e atuação em outras regiões. Também, que possam considerar o relacionamento entre cooperativas e associados, devido a relevância dessa relação para potencialização dos negócios.

Na sequência, o presente artigo apresenta a revisão da literatura que deu suporte a pesquisa empírica, a metodologia utilizada para seu desenvolvimento e os resultados obtidos. Por fim, apresenta-se as considerações finais, referências e os apêndices. 


\section{Revisão da Literatura}

O movimento cooperativista teve início após a segunda metade do século XVIII e início do século XIX, ligado ao desenvolvimento do capitalismo industrial na Europa. A primeira cooperativa surgiu em 1844 na Inglaterra e tinha o objetivo de aumentar o poder de compra de seus integrantes (SEBRAE, 2014). Atualmente, as cooperativas estão presentes em vários países e possuem participação ativa no desenvolvimento econômico mundial (MARTINS; LUCATO, 2018).

Cooperativa é uma união voluntária de pessoas com o objetivo de atender anseios e necessidades comuns relacionadas as questões socioeconômico e cultural, por meio de uma propriedade gerida de forma democrática e igualitária pelos seus próprios membros, onde o superávit obtido é revertido para a organização e/ou distribuído entre seus cooperados. São regidas pelos princípios: adesão livre; administração democrática; participação econômica dos membros; autonomia e independência; educação, formação e informação; inter cooperação; interesse pela comunidade. Também tem como base os valores da ajuda mútua, da auto responsabilidade, da igualdade, da democracia, da equidade e da solidariedade (ICA, s. d.; OCB, s. d.).

No Brasil, as cooperativas são regidas pela Lei 5.764 (BRASIL, 1971), que as instituem como sociedade de pessoas, sem fins lucrativos, não sujeitas a falência. Devem ter, no mínimo, 20 associados para sua constituição, todos com direito a um único voto. A adesão é livre a qualquer pessoa que se disponha a atender os objetivos sociais da cooperativa, exceto empresários que já operam no mesmo ramo de atividade. A lei também estabelece que havendo déficits ou sobras líquidas no exercício, a distribuição aos cooperados deverá ocorrer na proporção das atividades realizadas por eles na cooperativa.

Com vista a imposição legal do rateio de sobras e prejuízos, as cooperativas devem adotar procedimentos contábeis que produzam informações adequadas. Os demonstrativos contábeis devem permitir às partes interessadas, vislumbrar a real situação em que se encontra a cooperativa, facilitando tomadas de decisões eficientes evitando que contínuos prejuízos afetem econômica e financeiramente seus cooperados (CARVALHO, 2011; CARVALHO; BIALOSKORSKI NETO, 2008). Além disso, mesmo com objetivo social, o desempenho econômico-financeiro se faz necessário para garantir a sustentabilidade da cooperativa e que hajam recursos financeiros para investir em retornos sociais à comunidade de cooperados (BIALOSKORSKI NETO et al., 2006). Shamsuddin et al. (2017) destacam que os princípios e valores cooperativistas resultam em expectativas onde o desempenho econômico-financeiro está atrelado aos objetivos sociais da cooperativa e sem um bom desempenho o desenvolvimento social cooperativo será deficiente.

Nesse sentido, o acompanhamento do desempenho econômico-financeiro das cooperativas é uma postura estratégica que as permite planejar e executar ações esperadas socialmente, de curto e longo prazo, impulsionando-as para resultados positivos (CARVALHO, 2011). Essas ações podem ser corretivas ou fortalecedoras do desempenho observado, bem como, promovedoras de mudanças em determinados pontos da gestão administrativa, a fim de garantir o alcance dos resultados desejados, em consonância com os objetivos da cooperativa (OLIVEIRA, 2011). Os índices econômicofinanceiros são a forma mais comum de avaliar o desempenho econômico-financeiro das cooperativas, mesmo que acompanhados de outras variáveis (MARTINS; LUCATO, 2018; SHAMSUDDIN et al., 2017).

De acordo com Carvalho e Bialoskorski Neto (2008) existem vários indicadores econômicofinanceiros, porém nem todos são adequados as especificidades das cooperativas. Assim, ao analisarem os indicadores para avaliação do desempenho das cooperativas agrícolas brasileiras, os autores identificaram os três mais relevantes: liquidez, rentabilidade e endividamento. No quadro 1 apresenta-se esses indicadores, a fórmula para cálculo e sua função: 
Quadro 1 - Indicadores de liquidez, rentabilidade e endividamento

\begin{tabular}{|c|c|c|c|}
\hline \multicolumn{2}{|r|}{ Indicador } & Fórmula & Função \\
\hline \multirow{4}{*}{ 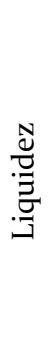 } & Liquidez Imediata & $\mathrm{LI}=\mathrm{Disp} / \mathrm{PC}$ & $\begin{array}{l}\text { Mede a capacidade do disponível no caixa para honrar os } \\
\text { compromissos de curto prazo. }\end{array}$ \\
\hline & Liquidez Seca & $\mathrm{LS}=($ AC-Est $) / \mathrm{PC}$ & $\begin{array}{l}\text { Mede a capacidade de pagamento das obrigações sem precisar } \\
\text { vender seus estoques. }\end{array}$ \\
\hline & Liquidez Corrente & $\mathrm{LC}=\mathrm{AC} / \mathrm{PC}$ & $\begin{array}{l}\text { Mede a capacidade total da cooperativa frente as suas } \\
\text { obrigações. }\end{array}$ \\
\hline & Liquidez Geral & $\begin{array}{l}\mathrm{LG}=(\mathrm{AC}+\mathrm{RLP}) / \\
\quad(\mathrm{PC}+\mathrm{PNC})\end{array}$ & Mede a saúde financeira da cooperativa no longo prazo. \\
\hline \multirow{4}{*}{ 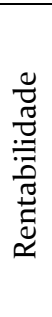 } & Giro do Ativo & $\mathrm{GA}=\mathrm{VL} / \mathrm{AT}$ & $\begin{array}{l}\text { Demonstra a eficiência com que a cooperativa utiliza seus } \\
\text { ativos. }\end{array}$ \\
\hline & $\begin{array}{l}\text { Rentabilidade do } \\
\text { Ativo }\end{array}$ & $\mathrm{RA}=\mathrm{LL} / \mathrm{AT}$ & Apresenta o retorno de cada real investido na cooperativa. \\
\hline & Rentabilidade do PL & $\mathrm{RPL}=\mathrm{LL} / \mathrm{PL}$ & $\begin{array}{l}\text { Demonstra o rendimento que o cooperado obteve sobre seu } \\
\text { capital investido. }\end{array}$ \\
\hline & Margem Líquida & $\mathrm{ML}=\mathrm{LL} / \mathrm{VL}$ & Apresenta a média de lucro gerado para cada real vendido. \\
\hline \multirow{4}{*}{ 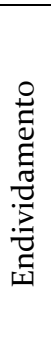 } & Participação do PL & $\mathrm{PPL}=\mathrm{PL} / \mathrm{AT}$ & $\begin{array}{l}\text { Demonstra o quanto do total do patrimônio da cooperativa é } \\
\text { financiado pelo patrimônio líquido. }\end{array}$ \\
\hline & $\begin{array}{l}\text { Composição do } \\
\text { Endividamento }\end{array}$ & $\mathrm{CE}=\mathrm{PC} / \mathrm{CT}$ & $\begin{array}{l}\text { Demonstra o valor percentual de todo o passivo da cooperativa } \\
\text { que será pago no curto prazo. }\end{array}$ \\
\hline & $\begin{array}{l}\text { Grau do } \\
\text { Endividamento }\end{array}$ & $\mathrm{GE}=\mathrm{CT} / \mathrm{PL}$ & $\begin{array}{l}\text { Mostra o quanto de capital de terceiros a cooperativa possui em } \\
\text { relação ao capital próprio. }\end{array}$ \\
\hline & Imobilização do PL & $\mathrm{IPL}=\mathrm{AP} / \mathrm{PL}$ & $\begin{array}{l}\text { Mostra o quanto do patrimônio líquido está investido em } \\
\text { imobilização. }\end{array}$ \\
\hline
\end{tabular}

Fonte: Assaf Neto e Lima (2014); Carvalho e Bialoskorski Neto (2008); Silva (2013).

Assaf Neto e Lima (2014) destacam os indicadores pertencentes ao grupo que mede o nível de atividade, conforme apresentado no quadro 2 :

Quadro 2 - Relação de indicadores de nível de atividades

\begin{tabular}{|l|c|l|}
\hline \multicolumn{1}{|c|}{ Indicador } & Fórmula & \multicolumn{1}{c|}{ Função } \\
\hline $\begin{array}{l}\text { Prazo Médio de Pagamento } \\
\text { das Compras }\end{array}$ & $\mathrm{PMPC}=($ Fornx36o $) / \mathrm{Co}$ & $\begin{array}{l}\text { Mede a média de quantos dias a cooperativa demora para } \\
\text { pagar as suas compras. }\end{array}$ \\
\hline $\begin{array}{l}\text { Prazo Médio de Rotação dos } \\
\text { Estoques }\end{array}$ & $\mathrm{PMRE}=($ Estx36o $) / \mathrm{CMV}$ & $\begin{array}{l}\text { Mede a média de quantos dias que a cooperativa leva para } \\
\text { vender seus estoques. }\end{array}$ \\
\hline $\begin{array}{l}\text { Prazo Médio para } \\
\text { Recebimento das Vendas }\end{array}$ & $\mathrm{PMRV=DRecx360/VB}$ & $\begin{array}{l}\text { Mede a média de quantos dias que a cooperativa demora } \\
\text { para receber de seus clientes. }\end{array}$ \\
\hline Posicionamento Relativo & $\mathrm{PR}=(\mathrm{PMRE}+\mathrm{PMRV})$ & $\begin{array}{l}\text { Indica a relação entre os prazos totais de venda, de } \\
\text { recebimento os prazos de pagamento dos fornecedores. }\end{array}$ \\
\hline Ciclo Operacional & $\mathrm{CO}=\mathrm{PMRE}+\mathrm{PMRV}$ & $\begin{array}{l}\text { Mostra o período das operações da cooperativa, desde as } \\
\text { compras até os recebimentos. }\end{array}$ \\
\hline Ciclo Financeiro & $\mathrm{CF}=\mathrm{CO}-\mathrm{PMPC}$ & $\begin{array}{l}\text { Mostra o tempo de pagamento aos fornecedores até o } \\
\text { recebimento das vendas. }\end{array}$ \\
\hline
\end{tabular}

Fonte: Assaf Neto e Lima (2014); Silva (2013).

As cooperativas, assim como as demais organizações, estão sujeitas a fatores ambientais e mercadológicos que podem afetar seus resultados e que, neste estudo, foram analisados para averiguar a interferência deles no desempenho econômico-financeiro das cooperativas. Dentre esses fatores, destacam-se os apresentados no quadro 3: 
Quadro 3- Fatores ambientais e mercadológicos

\begin{tabular}{|c|c|}
\hline Fatores & Descrição \\
\hline $\begin{array}{c}\text { Crises } \\
\text { Econômicas }\end{array}$ & $\begin{array}{l}\text { Martins e Lucato (2014) destacam que no passado, investimentos governamentais resultaram } \\
\text { no crescimento das cooperativas agrícolas brasileiras. A partir da década de 1980, após uma } \\
\text { série de crises econômicas, o governo deixou de ser o principal investidor ficando as } \\
\text { cooperativas com o desafio de adotar estratégias alternativas para sua sustentabilidade a } \\
\text { longo prazo. Os cenários de crise derivam de outras crises, sejam econômica, política ou } \\
\text { moral e estão ligados ao baixo crescimento ou desenvolvimento de um país; dura mais que } \\
\text { uma recessão e menos do que uma depressão (PAULA; PIRES, 2017; PIGNATA; CARVALHO, } \\
\text { 2015). }\end{array}$ \\
\hline $\begin{array}{l}\text { Variações } \\
\text { Cambiais }\end{array}$ & $\begin{array}{l}\text { As cooperativas agrícolas são diretamente influenciadas pela taxa de câmbio. Nakabashi } \\
\text { (2008) destaca a importância do câmbio nas relações de comércio exterior, haja vista } \\
\text { produzirem mudanças nos preços domésticos em relação aos externos refletindo no } \\
\text { favorecimento da exportação ou importação. }\end{array}$ \\
\hline Chuvas & $\begin{array}{l}\text { As chuvas são importantes para qualquer tipo de cultivo, porém, a dependência das chuvas } \\
\text { para o sucesso das plantações gera medo e incertezas nos agricultores e, consequentemente, } \\
\text { nas cooperativas agrícolas (PORTAL, 2019). }\end{array}$ \\
\hline Inflação & $\begin{array}{l}\text { Quando há equilíbrio na economia, se permite antecipar que os preços dos produtos } \\
\text { agropecuários se manterão estáveis ou até se apresentarão deflação. Caso contrário, havendo } \\
\text { inflação elevada há um desiquilíbrio no mercado que também afeta os negociadores desses } \\
\text { produtos, como as cooperativas agrícolas (MENDONÇA, 2006; SOCIEDADE NACIONAL } \\
\text { AGRÍCOLA [SNA], 2017). }\end{array}$ \\
\hline
\end{tabular}

Fonte: Martins e Lucato (2014); Mendença (2006); Nakabashi (2008); Paula e Pires (2017); Pignata e Carvalho (2015); Portal (2019); SNA (2017).

Outros fatores como o preço dos insumos, a cotação dos produtos comercializados e o histórico das safras são fatores mercadológicos e ambientais que podem ter afetado o desempenho econômico-financeiro das cooperativas estudadas. Quanto ao preço dos insumos, os adubos são considerados commodities, que têm seus preços estabelecidos pelo mercado internacional, tornandoos dependentes de preços incertos devido as oscilações na taxa de câmbio (MARTINS; LUCATO, 2014). Quanto a cotação dos produtos comercializados, a soja, que é uma das principais commodities negociadas no mercado internacional (SECRETARIA DE PLANEJAMENTO, ORÇAMENTO E GESTÃo [SPOG], s. d), é comercializada pelas cooperativas deste estudo e seu preço é influenciado pelas oscilações na taxa de câmbio. No mesmo sentido, as informações levantadas pelo histórico das safras dos grãos fornecem subsídios as partes interessadas das cooperativas para tomada de decisão (CAMPANHA NACIONAL DE ABASTECIMENTO [CONAB], s. d.). Destaca-se que, entre todos os países que produzem soja, o Brasil é o segundo maior produtor mundial e entre todos os estados brasileiros, o Rio Grande do Sul é o terceiro maior produtor (SPOG, s. d). Porém, esses fatores não puderam ser considerados na pesquisa pela não obtenção dos dados para o período completo da série de análise.

\section{Procedimentos Metodológicos}

A presente pesquisa classifica-se, quanto aos fins, como aplicada e exploratória. Quanto aos meios de investigação utilizados, classifica-se como documental e estudo de caso duplo. Quanto a abordagem, a pesquisa é quantitativa, devido à realização de cálculos e testes estatísticos para obtenção dos índices e a correlação destes com os fatores ambientais e mercadológicos (VERGARA, 2014).

O estudo de caso duplo foi realizado em duas cooperativas agropecuárias localizadas no Estado do Rio Grande do Sul, escolhidas por acessibilidade e pelas suas semelhanças. Ambas cooperativas tem porte similar, tanto na capacidade de recebimento de grãos quanto de faturamento. Atuam na mesma região do estado, tendo enfrentado as mesmas condições ambientais e mercadológicas, sejam estas favoráveis ou de maiores dificuldades. 
A cooperativa "A" foi fundada em 1956 e está presente em 13 municípios do estado do Rio Grande do Sul. Tem como atividades principais o recebimento, beneficiamento, armazenagem, industrialização e comercialização de soja, trigo, milho e girassol. Comercializa sementes de soja, trigo, milho e aveia, além de fertilizantes, corretivos e defensivos para a lavoura. Possui 21 unidades de recebimento de grãos, das quais 15 operam na comercialização de insumos. Também industrializa parte dos produtos recebidos dos associados, produzindo farinhas de trigo, massas de pizzas e lasanhas, rações e concentrados para suínos, bovinos e aves. No varejo, opera com 15 supermercados e uma loja de agropecuária. Presta assistência técnica agropecuária ao quadro social, através de agrônomos, técnicos em agropecuária e veterinários, disponibilizando farmácias veterinárias.

A cooperativa "B" foi fundada em 1957 e situa-se em 13 municípios gaúchos. Tem 23 unidades de recebimento de grãos, duas indústrias, uma de arroz e outra de rações. Também dispõe de uma unidade de beneficiamento de sementes com dois centros industriais de tratamento de sementes, laboratório de sementes e laboratório de solos. Possui creche de suínos, dois supermercados, três postos de combustíveis, um centro agropecuário, nove lojas de consumo/veterinária e 12 lojas de insumos. Dispõe de assistência técnica formada por agrônomos, veterinários e técnicos agrícolas qualificados e treinados periodicamente para levar novas tecnologias aos associados, permitindo que eles produzam mais em suas propriedades e, consequentemente, entreguem mais produtos a cooperativa.

A coleta de dados ocorreu por meio das demonstrações contábeis das cooperativas, do período de 1997 a 2016, bem como outros documentos disponibilizados pelas mesmas. Além disso, foram feitas observações nas rotinas das cooperativas, sem que houvesse intervenção dos pesquisadores. Por meio de entrevistas semiestruturadas aos gestores, se complementou as informações obtidas nos documentos e nas observações feitas. Já a coleta das informações ambientais e mercadológicas foram feitas por meio de buscas de informações em páginas eletrônicas de Internet, por exemplo: crises econômicas (WIKIPÉDIA, s. d.), variações cambiais (IPEA, s. d.), inflação (IBGE, s. d.) e histórico de chuvas (INMET, s. d.).

Os dados coletados a partir das demonstrações contábeis das cooperativas, mais especificamente no balanço patrimonial (BP) e na demonstração do resultado do exercício (DRE), foram tratados por meio de cálculos e recálculos matemáticos e estatísticos (YAMAMOTO; AKAMINE, 2009), para a obtenção dos índices econômico-financeiros. Esses, por sua vez, foram calculados por meio do Software Excel. Além disso, se utilizou de análise de correlação para verificar a relação existente entre os efeitos dos fatores ambientais e mercadológicos nos grupos de contas das demonstrações contábeis e nos índices econômico-financeiros encontrados (GUJARATI; PORTER, 2011). Essa análise foi feita por meio do software Eviews 9.5.

Com os dados obtidos pelas entrevistas aos gestores das cooperativas, se utilizou a forma qualitativa de análise, por meio de técnica de análise de conteúdo (CRESWELL, 2010). Essa técnica também foi utilizada para classificar os anos de crises econômicas, quando se utilizou de uma variável dummy na análise de correlação, onde um significou ano de crise e zero, não crise. O mesmo procedimento foi adotado para identificar anos com chuva e anos com falta de chuva suficiente para a produção agrícola.

\section{Apresentação e Discussão dos Resultados}

Neste tópico são apresentados os resultados da pesquisa. Inicialmente constam os índices econômico-financeiros abrangendo liquidez, rentabilidade, endividamento e nível de atividade. Na sequência se apresenta o resultado da análise de correlação entre os indicadores de uma mesma cooperativa, entre as cooperativas e dos índices econômico-financeiros com os fatores ambientais e mercadológicos.

\subsection{Indicadores econômico-financeiros das cooperativas}

Incialmente, apresenta-se os resultados obtidos com os indicadores que demonstram a liquidez das cooperativas. Para interpretação de cada indicador, considera-se que quanto maior for o índice, melhor é a liquidez da cooperativa (ASSAF NETO; LIMA, 2014). Na Tabela 1 expõe-se os 
resultados encontrados para os indicadores de liquidez geral (LG), liquidez corrente (LC), liquidez seca (LS) e liquidez imediata (LI) das duas cooperativas agrícolas.

Tabela 1 - Indicadores de liquidez

\begin{tabular}{l|cccc|cccc}
\hline \multirow{2}{*}{ Ano } & \multicolumn{4}{|c}{ Cooperativa A } & \multicolumn{4}{c}{ Cooperativa B } \\
\cline { 2 - 8 } & LG & LC & LS & LI & LG & LC & LS & LI \\
\hline 1997 & 0,68 & 1,36 & 0,63 & 0,08 & 0,52 & 0,86 & 0,46 & 0,04 \\
1998 & 0,70 & 1,26 & 0,79 & 0,05 & 0,61 & 1,08 & 0,44 & 0,06 \\
1999 & 0,85 & 1,16 & 0,56 & 0,08 & 0,65 & 1,08 & 0,52 & 0,03 \\
2000 & 0,89 & 1,10 & 0,62 & 0,11 & 0,68 & 1,30 & 0,77 & 0,08 \\
2001 & 0,78 & 0,90 & 0,54 & 0,12 & 0,74 & 1,56 & 0,76 & 0,12 \\
\hline 2002 & 0,63 & 0,78 & 0,46 & 0,10 & 0,84 & 1,93 & 0,96 & 0,14 \\
2003 & 0,77 & 0,92 & 0,49 & 0,06 & 0,92 & 1,49 & 0,71 & 0,12 \\
2004 & 0,80 & 0,96 & 0,63 & 0,06 & 0,95 & 1,63 & 0,91 & 0,13 \\
2005 & 0,70 & 0,79 & 0,47 & 0,07 & 0,93 & 1,73 & 0,98 & 0,19 \\
2006 & 0,65 & 0,67 & 0,33 & 0,04 & 0,93 & 1,68 & 0,81 & 0,16 \\
\hline 2007 & 0,83 & 0,90 & 0,74 & 0,01 & 1,06 & 1,41 & 0,83 & 0,12 \\
2008 & 0,81 & 0,72 & 0,38 & 0,01 & 1,09 & 1,60 & 1,11 & 0,32 \\
2009 & 0,75 & 0,25 & 0,20 & 0,02 & 1,06 & 1,65 & 1,19 & 0,43 \\
2010 & 0,87 & 0,23 & 0,19 & 0,01 & 1,09 & 1,58 & 0,79 & 0,16 \\
2011 & 0,93 & 0,24 & 0,20 & 0,01 & 1,10 & 1,59 & 1,19 & 0,11 \\
\hline 2012 & 0,93 & 0,23 & 0,19 & 0,01 & 1,23 & 1,82 & 1,37 & 0,28 \\
2013 & 0,93 & 0,17 & 0,14 & 0,01 & 1,25 & 1,84 & 1,27 & 0,46 \\
2014 & 0,74 & 0,11 & 0,09 & 0,00 & 1,29 & 1,78 & 1,10 & 0,18 \\
2015 & 0,92 & 0,09 & 0,08 & 0,00 & 1,42 & 1,74 & 1,01 & 0,23 \\
2016 & 1,04 & 0,09 & 0,07 & 0,00 & 1,44 & 1,71 & 1,00 & 0,19 \\
\hline
\end{tabular}

Fonte: Dados da pesquisa.

Verifica-se que nos cinco primeiros anos, a cooperativa A apresenta os indicadores de liquidez maiores do que da cooperativa $B$, mas nos anos seguintes nota-se uma inversão e a cooperativa B aumenta significativamente seus índices de liquidez enquanto a cooperativa A os perde gradativamente.

Na liquidez corrente da cooperativa A, é possível observar o declínio dos índices a partir do segundo ano, finalizando os dois últimos com o,o9. Já a liquidez corrente da cooperativa B apresenta patamares satisfatórios, visto que desde o segundo ano apresenta índices acima de 1 permanecendo assim até o final do período analisado. Destaca-se que, os resultados deste estudo diferem de Lopes (2009), onde os obtidos para as cooperativas Cotrisel e Camnpal são bons para ambas por estarem constantemente acima de 1 no período examinado.

Em 2014, a cooperativa A entrou em liquidação e, a partir desse ano, a liquidez imediata se apresenta zerada demonstrando sua incapacidade de saldar seus compromissos. Na cooperativa B, o referido índice apresentou pouca oscilação e valores baixos. Por outro lado, eles se configuram maiores em comparação aos valores da cooperativa A, significando que a alocação dos recursos garante a liquidez em qualquer situação.

$\mathrm{Na}$ cooperativa A, somente o indicador de liquidez geral apresentou crescimento finalizando o período analisado com índice um pouco maior a 1. Já a cooperativa $B$, desde o início os valores são crescentes havendo pequeno declínio a partir de 2005 mantido no período seguinte. A partir de 2007 torna a elevar-se, apesar das oscilações, mas sempre acima de 1. O cenário evidenciado em ambas cooperativas se difere daquele observado por Lopes (2009) nas cooperativas Cotrisel e Camnpal, visto que essas apresentam liquidez geral acima de 1 em todo o período examinado, enquanto as cooperativa A e B, apresentam períodos onde é inferior a 1.

A liquidez seca da cooperativa A, apresenta índices constantemente baixos, variando para mais ou para menos, estagnando-se em o,o1 nos últimos quatro anos antes da liquidação da cooperativa, em 2014, ano a partir do qual apresentou índices zerados. Já a liquidez seca da cooperativa $\mathrm{B}$ cresceu desde o terceiro ano e mesmo havendo períodos de declínios, seus valores são razoavelmente altos chegando, a partir de 2011, a índices igual ou superior a 1. Cabe destacar que o 
resultado obtido neste estudo difere do observado na pesquisa de Farias et al. (2019), onde as duas cooperativas agropecuárias analisadas apresentam liquidez seca menor do que 1. Por outro lado, ambos estudos concordam que uma cooperativa apresenta uma saúde financeira melhor que a outra.

A liquidez das cooperativas, a médio e longo prazo, está relacionada à lucratividade das suas operações (SILVA, 2013). Logo, seria necessário que a cooperativa A ajustasse seus custos e se voltasse ao quadro social com ênfase ao fortalecimento dos vínculos cooperativistas, dando credibilidade a organização e voltando a operar com volumes mais elevados de vendas, aumentando por consequência os índices de liquidez. Ressalta-se que quanto maior for a liquidez da cooperativa, menor o risco de descumprimento de suas obrigações e dificuldades futuras (CARVALHO; BIALOSKORSKI NETO, 2008).

$\mathrm{Na}$ Tabela 2 tem-se os indicadores de rentabilidade das cooperativas composto pelo giro do ativo (GA), rentabilidade do ativo (RA), rentabilidade do patrimônio líquido (RPL) e a margem liquida (ML).

Tabela 2 - Indicadores da rentabilidade

\begin{tabular}{c|cccc|cccc}
\hline \multirow{2}{*}{ Ano } & \multicolumn{4}{|c|}{ Cooperativa A } & \multicolumn{4}{c}{ Cooperativa B } \\
\cline { 2 - 8 } & GA & RA (\%) & RPL (\%) & ML (\%) & GA & RA (\%) & RPL (\%) & ML (\%) \\
\hline 1997 & 2,16 & $(5,40)$ & $(11,38)$ & $(2,50)$ & 1,29 & $(13,89)$ & $(118,96)$ & $(10,74)$ \\
1998 & 1,97 & $(5,40)$ & $(14,31)$ & $(2,74)$ & 1,33 & 0,31 & 2,98 & 0,23 \\
1999 & 1,96 & $(2,56)$ & $(6,00)$ & $(1,31)$ & 1,34 & 2,44 & 20,81 & 1,82 \\
2000 & 1,80 & $(2,40)$ & $(6,58)$ & $(1,34)$ & 1,45 & 3,31 & 31,50 & 2,28 \\
2001 & 2,90 & $(2,53)$ & $(8,73)$ & $(0,87)$ & 2,13 & 6,31 & 38,97 & 2,95 \\
\hline 2002 & 1,91 & $(5,12)$ & $(17,51)$ & $(2,68)$ & 2,25 & 6,66 & 35,40 & 2,97 \\
2003 & 2,34 & 0,25 & 1,21 & 0,11 & 2,47 & 4,36 & 24,97 & 1,77 \\
2004 & 1,97 & 2,45 & 11,71 & 1,24 & 2,02 & 5,02 & 23,24 & 2,49 \\
2005 & 1,47 & $(2,20)$ & $(9,19)$ & $(1,50)$ & 1,33 & 1,15 & 4,66 & 0,86 \\
2006 & 1,92 & $(11,49)$ & $(85,73)$ & $(5,99)$ & 1,53 & 2,82 & 10,38 & 1,84 \\
\hline 2007 & 1,60 & $(2,18)$ & $(35,83)$ & $(1,36)$ & 1,99 & 6,55 & 24,80 & 3,29 \\
2008 & 1,76 & $(1,67)$ & $(34,05)$ & $(0,95)$ & 2,61 & 8,37 & 24,52 & 3,21 \\
2009 & 1,40 & $(18,73)$ & $(551,4)$ & $(13,38)$ & 2,30 & 5,71 & 16,54 & 2,48 \\
2010 & 0,29 & $(9,01)$ & $(90,48)$ & $(31,57)$ & 1,99 & 6,76 & 21,52 & 3,40 \\
2011 & 0,15 & $(3,88)$ & $(12,09)$ & $(25,56)$ & 1,94 & 4,67 & 18,98 & 2,40 \\
\hline 2012 & 0,16 & $(5,18)$ & $(17,59)$ & $(32,04)$ & 1,72 & 9,74 & 39,11 & 5,67 \\
2013 & 0,16 & $(6,06)$ & $(22,49)$ & $(37,37)$ & 2,30 & 8,46 & 26,66 & 3,68 \\
2014 & 0,16 & $(30,69)$ & $(1477)$ & $(191,2)$ & 2,30 & 7,59 & 23,39 & 3,30 \\
2015 & 0,13 & $(10,53)$ & $(97,24)$ & $(79,40)$ & 2,54 & 8,94 & 19,04 & 3,52 \\
2016 & 0,13 & $(2,02)$ & $(13,20)$ & $(14,98)$ & 2,49 & 6,21 & 13,11 & 2,50 \\
\hline
\end{tabular}

Fonte: Dados da pesquisa.

Na cooperativa A, nota-se um declínio no giro do ativo, principalmente a partir de 2010, onde mantém-se inferior a 1 até o final do período. Já na cooperativa B, o comportamento do giro do ativo é diferente, pois os índices se mantêm superior a 1 mesmo havendo oscilação entre um ano e o outro.

A rentabilidade da cooperativa A, tanto do ativo quanto do patrimônio líquido, apresentou-se negativa na maioria dos períodos analisados, com exceção dos anos de 2003 e 2004, devido aos resultados negativos. Na cooperativa $B$, a rentabilidade, tanto do ativo quanto do patrimônio líquido, iniciou negativa, mas evoluíram positivamente nos anos seguintes. Porém, ainda que permaneçam positivas, demonstram pouco crescimento, possivelmente pelo expressivo valor do patrimônio líquido da cooperativa. Diferente do que se evidencia neste estudo, Farias et al. (2019) constataram valores positivos para ambos indicadores, ainda que baixos, tanto para cooperativa Beta quanto a cooperativa Gama.

A margem líquida da cooperativa $A$, que representa as sobras em relação as vendas, também é negativa em quase todo o período. Na cooperativa $\mathrm{B}$, a margem líquida manteve-se com altos índices durante a maioria do período analisado, principalmente entre os anos de 2007 e 2015. Por um lado, estas evidencias se assemelham aos encontrados por Farias et al. (2019), ao demonstrar a superioridade de uma cooperativa em comparação a outra, no sentindo de possuir bons índices de 
margem líquida. De outro lado, os estudos se diferem, pois, nenhuma das duas cooperativas examinadas pelos referidos autores apresentam valores negativos.

De modo geral, pelos índices de rentabilidade da cooperativa A é possível visualizar seu estado de desiquilibro econômico-financeiro, pois durante todo o período analisado os resultados são insatisfatórios. Por outro lado, a cooperativa B demonstrou-se sustentável e equilibrada ao longo do período analisado e, consequentemente, consolidada junto à comunidade onde está inserida, pelos impactos econômico e social proporcionados (LONDERO; BIALOSKORSKI NETO, 2017; SUCHMAN, 1995). Destaca-se que, quanto maior for os índices de rentabilidade, melhor será sua saúde financeira indicando eficiência no uso dos recursos investidos na cooperativa, boa lucratividade mediante seu faturamento, seus investimentos e capital dos cooperados (SILVA, 2013).

Cabe salientar que alguns estudos (BIALOSKORSKI NETO, et al., 20o6; CARVALHO; BIALOSKORSKI NETO, 2008; FARIAS et al., 2019) alertam para possibilidade de distorção na análise dos indicadores de rentabilidade que tomam por base as sobras. Argumentam que o lucro não é o objetivo das cooperativas, por isso, em alguns casos o resultado final do exercício pode não apresentar sobras, o que poderia ser explicado pela maximização dos preços ou serviços oferecidos aos cooperados. Isso significaria distribuição dos resultados durante as atividades da cooperativa.

Na sequência, apresenta-se a Tabela 3 com os indicadores do endividamento e estrutura de capital: composição do endividamento (CE), grau do endividamento (GE), imobilização do patrimônio líquido (IPL) e participação do patrimônio líquido (PPL).

Tabela 3 - Indicadores de endividamento e estrutura de capital

\begin{tabular}{c|cccc|cccc}
\hline \multirow{2}{*}{ Ano } & \multicolumn{4}{|c}{ Cooperativa A } & \multicolumn{4}{c}{ Cooperativa B } \\
\cline { 2 - 9 } & CE (\%) & GE (\%) & IPL (\%) & PPL (\%) & CE (\%) & GE (\%) & IPL (\%) & PPL (\%) \\
\hline 1997 & 51 & 53 & 134 & 47 & 32 & 88 & 453 & 11 \\
1998 & 56 & 62 & 148 & 38 & 33 & 89 & 430 & 10 \\
1999 & 72 & 57 & 119 & 43 & 36 & 88 & 355 & 11 \\
2000 & 77 & 64 & 117 & 36 & 41 & 89 & 368 & 10 \\
2001 & 74 & 71 & 151 & 29 & 37 & 83 & 233 & 16 \\
\hline 2002 & 63 & 71 & 190 & 29 & 38 & 81 & 170 & 18 \\
2003 & 73 & 80 & 181 & 20 & 54 & 82 & 136 & 17 \\
2004 & 76 & 79 & 174 & 21 & 50 & 78 & 116 & 21 \\
2005 & 61 & 76 & 195 & 24 & 44 & 75 & 119 & 24 \\
2006 & 68 & 87 & 325 & 13 & 43 & 72 & 119 & 24 \\
\hline 2007 & 85 & 94 & 356 & 6 & 64 & 73 & 82 & 27 \\
2008 & 72 & 95 & 444 & 5 & 54 & 65 & 82 & 26 \\
2009 & 76 & 97 & 812 & 3 & 49 & 65 & 88 & 34 \\
2010 & 62 & 90 & 204 & 10 & 56 & 68 & 79 & 34 \\
2011 & 55 & 68 & 113 & 32 & 57 & 74 & 90 & 31 \\
\hline 2012 & 57 & 71 & 114 & 29 & 57 & 72 & 78 & 24 \\
2013 & 68 & 73 & 116 & 27 & 56 & 65 & 79 & 24 \\
2014 & 72 & 102 & - & $(2)$ & 60 & 64 & 70 & 31 \\
2015 & 78 & 89 & 166 & 11 & 76 & 53 & 52 & 32 \\
2016 & 78 & 85 & 78 & 15 & 83 & 52 & 50 & 47 \\
\hline
\end{tabular}

Fonte: Dados da pesquisa.

Na cooperativa A, pelos indicador composição do endividamento, percebe-se o aumento das dívidas de curto prazo em relação ao montante devedor. Além disso, os índices da cooperativa A, na maioria do período examinado, são maiores do que os valores apresentados pela cooperativa B. Em ambas cooperativas, observa-se oscilações de crescimento e declínio no referido indicador, mas sempre em patamares que caracterizam uma evolução negativa, pois aumenta sua representatividade quando o melhor seria apresentar índices menores indicando menos obrigações a serem pagas a curto prazo e menor responsabilidade em obter recursos, igualmente a curto prazo (SILVA, 2013). De modo semelhante foi observado por Farias et al. (2019) ao constarem que a composição de endividamento das cooperativas Beta e Gama configuram-se diferente do que seria o ideal.

Quanto ao grau do endividamento, na cooperativa A este indicador demonstra um cenário negativo, pois apresenta variações crescentes ao longo dos anos estando em uma situação onde a 
liquidez é similarmente negativa. Nesse caso, melhor seria manter o endividamento em níveis mais baixos, reduzindo a dependência financeira de capital de terceiros para custear suas atividades a fim de não comprometer a saúde financeira da cooperativa (SILVA, 2013). Por outro lado, na cooperativa B, observa-se uma retração significativa, pois inicialmente o indicador representava cerca de $88 \%$ do patrimônio e ao final representou $52 \%$, evidenciando o grau de independência da cooperativa em consequência da expressiva ampliação do financiamento pelo patrimônio líquido, que migrou dos $11 \%$ para quase $50 \%$ durante o período analisado. Esses resultados são semelhantes aos encontrados por Lopes (2009), visto que a cooperativa Camnpal apresenta situação distinta da cooperativa Cotrisel, por possuir um grau de endividamento menos satisfatório que a outra.

$\mathrm{Na}$ cooperativa A, o indicador imobilização do patrimônio líquido é elevado, chegando a pouco mais de $800 \%$ no ano de 2009. O mesmo acontece com a cooperativa B, principalmente, nos primeiros cinco anos, porém, notou-se uma tendência de redução ao longo do período. Na cooperativa B, este indicador apresenta-se em constante diminuição. Em 1997 o imobilizado representava mais de $450 \%$ do patrimônio líquido, passando para menos de $100 \%$ em 2007 e atingindo $50 \%$ no final do período analisado. Isto indica uma exclusão progressiva do financiamento do imobilizado por contas do passivo, o que aumenta significativamente a eficiência ou a competitividade da cooperativa. Situação semelhante é percebida no estudo de Gruber, Gimenes e Gimenes (2009), onde constatou que a cooperativa Lar possuía alto índice de imobilização do PL, denotando um risco ao financiamento e liquidez da organização, enquanto a cooperativa Copacol apresentou índice menor quando comparado com a primeira. Salienta-se que quanto menor for o indicador melhor será para a cooperativa, no sentido de refletir positivamente na sua liquidez (ASSAF NETO; LIMA, 2014).

O indicador participação do patrimônio líquido, apresenta comportamento distinto entre as cooperativas. Na cooperativa A, observa-se que há períodos de crescimentos, com $47 \%$ em 1997 e outros de declínio, atingindo $3 \%$ em 2009. Já na cooperativa $B$, nota-se pouca oscilação de um ano para outro, mantendo-se na faixa de pouco mais de $10 \%$ até 2003 , se elevando continuamente no decorrer dos anos seguintes, atingindo $47 \%$ em 2016. Considerando que esse índice indica o quanto o capital dos sócios financia o ativo total, entende-se que quanto mais alto, menores as dívidas e, portanto, positivo para a cooperativa (ASSAF NETO; LIMA, 2014).

Os indicadores referentes ao nível de atividade estão apresentados na Tabela 4: prazo médio de rotação do estoque (PMRE), prazo médio de recebimento das vendas (PMRV), prazo médio de pagamento de compras (PMPC), posicionamento relativo (PR), ciclo operacional (CO) e ciclo financeiro $(\mathrm{CF})$.

Tabela 4 - Indicadores do nível de atividade

\begin{tabular}{|c|c|c|c|c|c|c|c|c|c|c|c|c|}
\hline \multirow{2}{*}{ Ano } & \multicolumn{6}{|c|}{ Cooperativa A } & \multicolumn{6}{|c|}{ Cooperativa B } \\
\hline & PMRE & PMRV & PMPC & PR & $\mathrm{CO}$ & CF & PMRE & PMRV & PMPC & PR & $\mathrm{CO}$ & CF \\
\hline 1997 & - & - & - & - & - & - & - & - & - & - & - & - \\
\hline 1998 & 35 & 34 & 29 & 2 & 69 & 40 & 47 & 28 & 17 & 4 & 75 & 58 \\
\hline 1999 & 42 & 37 & 45 & 2 & 79 & 34 & 56 & 32 & 28 & 3 & 88 & 60 \\
\hline 2000 & 49 & 38 & 54 & 2 & 87 & 33 & 55 & 47 & 42 & 2 & 102 & 60 \\
\hline 2001 & 28 & 27 & 28 & 2 & 55 & 27 & 42 & 34 & 28 & 2 & 76 & 48 \\
\hline 2002 & 29 & 29 & 38 & 2 & 58 & 20 & 46 & 32 & 18 & 4 & 78 & 60 \\
\hline 2003 & 29 & 26 & 25 & 2 & 55 & 30 & 44 & 30 & 13 & 5 & 74 & 61 \\
\hline 2004 & 41 & 45 & 26 & 3 & 86 & $6 o$ & 63 & 49 & 19 & 5 & 112 & 93 \\
\hline 2005 & 49 & 58 & 38 & 3 & 107 & 69 & 90 & 79 & 27 & 6 & 169 & 142 \\
\hline 2006 & 33 & 26 & 39 & 2 & 59 & 20 & 74 & 54 & 20 & 6 & 128 & 108 \\
\hline 2007 & 26 & 69 & 55 & 2 & 95 & 40 & 49 & 42 & 19 & 4 & 91 & 72 \\
\hline 2008 & 43 & 72 & 66 & 2 & 115 & 49 & 35 & 42 & 17 & 4 & 77 & 60 \\
\hline 2009 & 49 & 50 & 76 & 1 & 99 & 23 & 26 & 38 & 14 & 4 & 64 & 50 \\
\hline 2010 & 47 & 110 & 353 & o & 157 & $(196)$ & 42 & 38 & 18 & 4 & 80 & 62 \\
\hline 2011 & 51 & 127 & 399 & o & 178 & $(221)$ & 41 & 58 & 16 & 6 & 99 & 83 \\
\hline 2012 & 48 & 117 & 269 & 1 & 165 & (104) & 37 & 81 & 20 & 5 & 118 & 98 \\
\hline 2013 & 46 & 112 & 229 & 1 & 158 & $(71)$ & 30 & 50 & 20 & 4 & 80 & 60 \\
\hline 2014 & 40 & 109 & 291 & 1 & 149 & $(142)$ & 35 & 42 & 20 & 3 & 77 & 57 \\
\hline 2015 & 34 & 99 & 332 & o & 133 & (199) & 40 & 42 & 24 & 3 & 82 & 58 \\
\hline 2016 & 32 & 93 & 311 & o & 125 & $(186)$ & 45 & 43 & 22 & 4 & 88 & 66 \\
\hline
\end{tabular}


Fonte: Dados da pesquisa.

Com os índices obtidos, percebe-se que a cooperativa B manteve seus prazos médios constantemente. Por outro lado, nos primeiros anos analisados, a rotação dos estoques da cooperativa A apresenta giro maior em comparação a cooperativa $\mathrm{B}$, havendo uma inversão de comportamento no período de 2008 a 2014. Destaca-se que quanto menor for os dias de giro do estoque, melhor para cooperativa por necessitar de menos recursos para suas operações (GRUBER et al., 2009), logo, a cooperativa B apresenta-se em condições mais favoráveis por apresentar dias de giro menores que a outra, ainda que ambas possuam prazos médios não elevados, semelhante aos resultados constatados por Gruber et al. (2009) onde ambas as cooperativas analisadas apresentavam prazos médios de estocagens eficientes.

No indicador que mede os prazos médios de recebimento, também se constata um comportamento distinto entre as cooperativas. Por exemplo, de 2000 a 2006 os prazos médios de recebimento da cooperativa $A$ são menores em relação aos da cooperativa $B$, mas a partir de 2007 até o fim do período analisado, a cooperativa A passa a estender expressivamente seus prazos resultando em médias maiores. Esse cenário se difere do observado por Gruber et al. (2009), pois mesmo a cooperativa Copacol apresentando prazo maior em relação a outra cooperativa, essa diferença é mínima e em ambas, esses prazos são menores do que os encontrados neste estudo.

Já nos prazos médios de pagamento, com exceção do ano de 2001 onde ambas cooperativas apresentam a mesma quantidade de dias, nos períodos analisados a cooperativa A apresenta prazos maiores em comparação a cooperativa $B$, o que também é visto nos resultados de Gruber et al. (2009). Destaca-se que apresentar um prazo médio de pagamento elevado é positivo para a cooperativa (ASSAF NETO; LIMA, 2014), porém, nesse caso, a elevação deve-se a falta de recursos, o que não é benéfico para a cooperativa. Ressalta-se que em vários anos anteriores a 2008, a cooperativa A trabalhou com prazos médios de pagamento das compras menor do que o recebimento das vendas, o que pode ter contribuído para a falta de liquidez nos períodos seguintes.

Em termos de posicionamento relativo, a cooperativa A apresenta índices menores do que a cooperativa B. Porém, para a cooperativa A essa análise fica prejudicada pela inadimplência em parte do período. Nota-se que para cooperativa B, o posicionamento variou todo o período analisado, mantendo-se superior a 1. Destaca-se que o indicador 1 serve de base para avaliar o posicionamento, logo, o resultado é bom quando for menor do que 1 e pior a medida que o valor encontrado é superior (MARION, 2002).

Com relação aos ciclos, verifica-se que até 2009 a cooperativa A atuava com ciclos financeiros altos, declinando significativamente a partir de 2010. Isto se justifica pela sua baixa liquidez no período motivando mudanças estratégicas nos negócios a partir de 2009, afetando os períodos posteriores. No entanto, até a referida data, este ciclo apresenta dias menores em comparação ao da cooperativa $\mathrm{B}$, havendo uma inversão a partir de 2010. Já no ciclo operacional, observa-se o mesmo comportamento até 2006, ou seja, este ciclo apresenta dias menores na cooperativa A em comparação a cooperativa B, havendo inversão a partir de 2007. Os resultados obtidos neste estudo, para ambos os ciclos, são semelhantes aos encontrado por Gruber et al. (2009), pois há notória diferença entre os dias que compõe os ciclos das cooperativas Lar e Copacol, sendo os da primeira menores em relação aos da segunda.

Cabe ressaltar que no período de 2004 a 2006 há elevação significativa nos ciclos da cooperativa B. Se considera que no ano de 2004, a elevação deu-se devido à queda do faturamento e que o ano de 2006 reflete o ano de 2004 aliado a constância nos prazos de pagamento. Quanto ao aumento constatado no clico operacional da cooperativa $A$, salienta-se que tal situação não é interessante, visto compor-se majoritariamente por aumento nos prazos de recebimento das vendas, o que implica em maior necessidade de capital de giro para a cooperativa (SILVA, 2013).

Complementarmente a análise dos indicadores, se avaliou as oscilações do faturamento bruto, sobras e evolução do patrimônio de ambas cooperativas. Esses resultados estão demonstrados na Figura 1. 
Figura 1 - Análise das oscilações entre a cooperativas A e cooperativa B

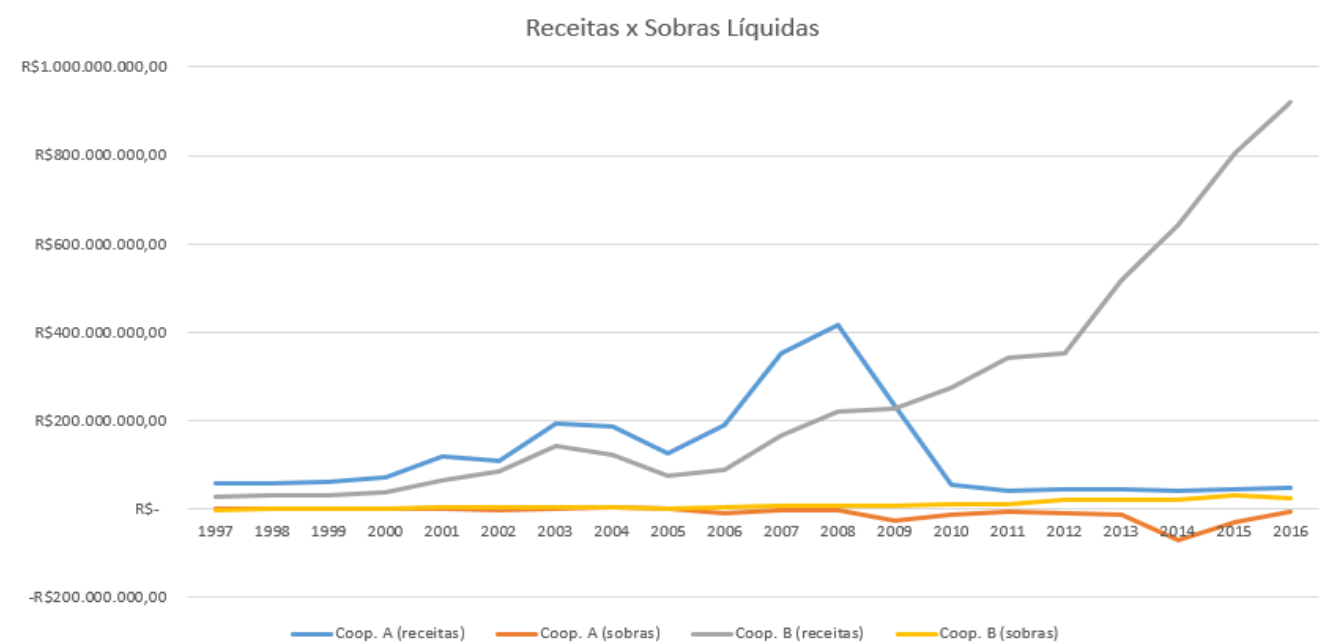

Fonte: Demonstrações contábeis das cooperativas.

Na cooperativa A houve degradação acentuada no volume do faturamento, principalmente no período de 2009 a 2010. Conforme informações obtidas nas entrevistas, tal situação se deve pela decisão administrativa de arrendar parte das unidades recebedoras de grãos, comprometendo a liquidez da cooperativa. Em consonância a queda do faturamento, os resultados também apresentam piora significativa a partir do momento em que há redução das receitas, indicando não haver reflexo dessa redução nos custos da cooperativa.

No mesmo período os resultados da cooperativa A pioram significativamente, o que se deve ao fato de alguns contratos não haverem sido reconhecidos pela contabilidade nos anos anteriores a 2014, ano em que a cooperativa aderiu ao processo de liquidação e realizou o lançamento dos mesmos, acarretando resultados financeiros negativos nos anos subsequentes devido ao reflexo dos encargos de tais contratos.

Por outro lado, na cooperativa B, se observa que a receita e as sobras apresentam-se harmônicas em todo o período analisado, podendo-se inferir a existência de ganho de competitividade da cooperativa se analisado que a receita avança de maneira vantajosa, assim como os resultados. Também se constata que os custos e despesas mantêm-se para tanto, altamente vinculados a evolução da receita, o que demonstra a eficiência da gestão.

\subsection{Análise de correlação}

Se procedeu 3 tipos de análise de correlação. A primeira foi entre as contas das Demonstrações Contábeis de cada uma das cooperativas. A segunda foi análise de correlação entre os índices das duas cooperativas e a terceira foi feita para observar se os fatores ambientais e mercadológicos afetaram os resultados das duas cooperativas. Destaca-se que se considerou significativamente correlacionadas aquelas variáveis que apresentaram valor maior do que 0,7 , tanto positiva quanto negativamente, e significância menor do que o,10.

Com relação a primeira análise de correlação se constatou que a cooperativa A apresenta correlação positiva e significativa nos resultados dos diversos anos, comparando um ano com o outro, desde 1997 até 2009. No ano de 2010 apresenta correlação positiva significativa apenas com o ano de 2009, porém em nível bem menor do que a correlação entre os anos anteriores, indicando uma ruptura nos resultados da cooperativa nesse ano. A partir de 2010 os resultados voltam a apresentar correlação positiva e significativa até 2016. Na cooperativa B, se percebe correlação positiva e significativa em toda a série de dados. Os resultados apresentados pela cooperativa no ano de 1997 ainda estão positiva e significativamente correlacionados com os resultados apresentados pela cooperativa no ano de 2016.

A segunda forma de correlação realizada, constituiu-se no cruzamento entre os índices calculados para as cooperativas A e B. Observa-se que as correlações identificadas entre os índices de 
uma mesma cooperativa podem ser observadas nos Apêndices A e B. Os índices que apresentaram correlação significativa estão resumidos na sequência.

O giro do ativo da cooperativa A está negativamente correlacionado com a Composição do endividamento da cooperativa B. O grau de imobilização do capital de terceiros da cooperativa A está positivamente correlacionado com a composição do endividamento da cooperativa B. O grau de imobilização do capital de terceiros da cooperativa B está positivamente correlacionado com o giro do ativo da cooperativa A e negativamente correlacionado com a composição do endividamento e o giro do ativo da cooperativa B e com o grau de imobilização do capital de terceiros da cooperativa A. A liquidez corrente da cooperativa A está positivamente correlacionado com o giro do ativo da cooperativa A e com o grau de imobilização do capital de terceiros da cooperativa B. Também está negativamente correlacionado com a composição do endividamento da cooperativa $\mathrm{B}$. A liquidez corrente da cooperativa B está negativamente correlacionada com o grau de imobilização do capital de terceiros da cooperativa B e com a liquidez corrente da cooperativa A. A liquidez geral da cooperativa B está positivamente correlacionada com a composição do endividamento e com a liquidez corrente da cooperativa B e com o grau de imobilização do capital de terceiros da cooperativa A. Também apresenta correlação negativa com o giro do ativo e com a liquidez corrente da cooperativa A e com o grau de imobilização do capital de terceiros da cooperativa B. O prazo médio de pagamento das compras da cooperativa A está positivamente correlacionado com a liquidez geral da cooperativa $\mathrm{B}$ e negativamente correlacionado com o giro do ativo e a liquidez corrente da cooperativa $\mathrm{A}$. O prazo médio de recebimento das vendas da cooperativa $\mathrm{A}$ está positivamente correlacionado com o prazo médio de pagamento das compras da cooperativa A e negativamente correlacionado com o giro do ativo da cooperativa A. E, a rentabilidade do Patrimônio Líquido da cooperativa B está negativamente correlacionado com a Rentabilidade do Ativo da Cooperativa B.

Destaca-se que o objetivo dessa análise de correlação foi verificar se os índices das cooperativas estavam tendo a mesma direção. No entanto, como pode-se observar, são poucos aqueles que demonstram correlação significativa, porém, foi negativa, como no caso do grau de imobilização do capital de terceiros e a liquidez corrente.

Entre indicadores de uma mesma cooperativa é relevante destacar a correlação negativa entre a composição do endividamento e o grau de imobilização do capital de terceiros da cooperativa B, isso significa que quanto maior a imobilização com capital de terceiros, menor é a participação desse capital no total das fontes da cooperativa. Isso significa dizer que o Patrimônio Líquido da cooperativa aumentou em uma proporção maior do que o imobilizado. Também se destaca a correlação negativa entre a rentabilidade do ativo e do patrimônio líquido da cooperativa $B$. Provavelmente pelo reflexo da inversão de participação de capital de terceiros por patrimônio líquido que aumentou significativamente no período e, portanto, os percentuais de rentabilidade diminuíram, sem serem negativos.

Os resultados da análise de correlação entre as variáveis ambientais e mercadológicas e os índices das cooperativas também estão apresentados nos Apêndices A e B. Em relação à cooperativa A não se identificou correlação estatisticamente significativa para nenhum dos índices com qualquer um dos fatores ambientais e mercadológicos. Portanto, pode-se inferir que esses fatores não interferem nos resultados dessa cooperativa, direcionando a responsabilidade dos resultados para a gestão da cooperativa, ou seja, para fatores internos. No que tange à cooperativa B, constata-se que a variação cambial (dólar) esteve correlacionada positivamente com o giro do ativo e com a liquidez corrente. Isso demonstra que quando houve elevação da cotação do dólar, também houve aumento no volume das vendas (em reais), que, por sua vez, refletiu em volume de ativo circulante aumentando a liquidez corrente. Por outro lado, a variação cambial esteve negativamente correlacionada com o grau de imobilização do capital de terceiros, provavelmente porque esses bens foram adquiridos dentro do Brasil, não sendo afetados diretamente pela variação da moeda. Por fim, se constata correlação positiva entre os próprios fatores ambientais e mercadológicos como é o caso da inflação com as crises e a variação do dólar com a inflação, o que parece coerente com os princípios macroeconômicos (MENDONÇA, 2006; PAULA; PIRES, 2017). 


\section{Considerações Finais}

Este estudo objetivou analisar o desempenho econômico-financeiro de duas cooperativas agrícolas, no período de 1997 a 2016, e identificar os fatores ambientais e mercadológicos que influenciaram nesses resultados. Para tanto, foram consultadas as demonstrações contábeis das cooperativas, e obtidos fatores externos representativos do ambiente e do mercado onde as cooperativas estão inseridas.

Destaca-se que ambas cooperativas vivenciam momentos distintos. A cooperativa B possui uma situação financeira mais confortável em relação a cooperativa A. Esta, por sua vez, apresentou piora a cada ano analisado a partir de 2009. Os níveis de liquidez, deixam claro este cenário, pois enquanto os índices da cooperativa B evoluíram positivamente, na cooperativa $A$ há redução significativa ano a ano. Nesta cooperativa, apenas a liquidez geral aumentou, o que se deve a transferência dos resultados negativos do patrimônio líquido para o ativo realizável a longo prazo, acarretando distorção no crescimento do indicador. Isto também se observa nos indicadores da rentabilidade, pois enquanto a cooperativa $\mathrm{A}$ os mantém negativos ou em níveis extremamente baixos, a cooperativa B demonstra-se lucrativa ao longo do período analisado.

Os indicadores relacionados ao endividamento e a estrutura de capital, expõem uma inversão entre as cooperativas. A cooperativa A se mostra financiada por capital de terceiros e a cooperativa B se estrutura nos próprios resultados. Tais indicadores vinculam-se aos de liquidez, pois quando o patrimônio é financiado por terceiros há comprometimento de recursos do ativo circulante, o que reduz a liquidez. Já os indicadores relativos aos prazos médios, demonstraram que a cooperativa A atua com prazos longos. Sem liquidez, esta cooperativa opera em níveis elevados de endividamento influenciando no aumento dos seus prazos. A cooperativa B também possui prazos alongados e seu posicionamento relativo se afasta do nível que seria o ideal.

A análise correlativa indicou menos correlação na cooperativa A do que na cooperativa B, ou seja, há menos vinculação entre a evolução das contas da cooperativa A. Na cooperativa B a análise correlativa indicou vinculação entre as contas, podendo-se inferir que a mesma se desenvolve baseada no patrimônio líquido com tendência de aumento na maior parte dos grupos de contas. Destaca-se que não houve correlações entre as variáveis dos fatores externos com os resultados e evolução do patrimônio das cooperativas, com exceção da variação cambial que esteve correlacionada positivamente com o giro do ativo e com a liquidez corrente da cooperativa B. Esses resultados permitem afirmar que esses fatores não interferiram significativamente nos resultados das cooperativas, no período analisado e, que muito provavelmente, sofreram influência apenas do meio interno, para o desempenho identificado. O que, por sua vez, pode justificar a diferença no desempenho econômico-financeiro entre as duas cooperativas, haja vista ambas possuírem características semelhante: tempo de vida e região de atuação, quadro de cooperados e exposição aos mesmos fatores externos.

Ressalta-se que atualmente a cooperativa A busca recuperar a credibilidade no mercado, com seus associados e com não cooperados, modificando suas atividades. Trata-se de um processo longo e demorado, com vários problemas de ordem financeira e operacional sendo juridicamente tratados para recuperação dos negócios e consequentemente da liquidez. Já a cooperativa B vem realizando investimentos visando aumentar sua competitividade e sua influência no mercado.

Por fim, a pesquisa limitou-se a um estudo de caso duplo, com indicadores de desempenho econômico-financeiros tradicionalmente usados na literatura, bem como, a análise de fatores externos atrelados ao cotidiano das cooperativas. Por isso, sugere-se estudos futuros considerando um número maior de cooperativas e a associação de outros indicadores que, juntamente aos indicadores tradicionais, possam medir o desempenho das cooperativas. Também se sugere o estudo de outros fatores internos e externo que possam interferir nos resultados das cooperativas. 


\section{Referências}

ASSAF NETO, A.; LIMA, F. G. Fundamentos de administração financeira. 2. ed. São Paulo: Atlas, 2014.

BIALOSKORSKI NETO, S.; NAGANO, M.S.; Costa, M.B. Utilização de redes neurais artificiais para avaliação sócio-econômica: uma aplicação em cooperativas. Revista de Administração (USP), v. 41, n. 1, p. 59-68, 2006.

BRASIL. Lei no 5.764, de 16 de dezembro de 1971. Define a Política Nacional de Cooperativismo, institui o regime jurídico das sociedades cooperativas, e dá outras providências. Disponível em: www.planalto.gov.br/ccivil_03/Leis/L5764.htm. Acesso em 18 set. 2017.

CAMPANHA NACIONAL DE ABASTECIMENTO. Safras. Disponível em: https://portaldeinformacoes.conab.gov.br/index.php/safras> Acesso em 16 de abr. 2018.

CARVALHO, A. D. O cooperativismo sob a ótica da gestão estratégica global. São Paulo: Baraúna, 2011

CARVALHO, F.L.; BIALOSKORSKI NETO, S. Performance indicators in agriculture cooperatives. Organizações Rurais \& Agroindústrias, v. 10, n. 3, p. 75-79, 2008.

CRESWELL, J. W. Projeto de pesquisa: métodos qualitativo, quantitativo e misto. 3. ed. Porto Alegre: Artmed, 2010.

FARIAS, E. S.; SANTOS, M. B.; BENTO, M. H. S.; FERREIRA, G. M. V.; WAKULICZ, G. J.; HÖHER, R. Indicadores econômico-financeiro: um paralelo em duas cooperativas agropecuárias do Rio Grande do Sul. Revista Interdisciplinar Cientifica Aplicada, v. 13, n .2, p. 97-177, 2019.

GIMENES, R.M.T.; URIBE-OPAZO, M.A. Previsão de insolvência de cooperativas agropecuárias por meio de modelos multivariados. Revista FAE, v. 4, n. 3, p. 65-78, 2001

GRUBER, R. R.; GIMENES, R. M. T.; GIMENES, F. M. P. As cooperativas agropecuárias frente à competitividade das sociedades anônimas: aspectos econômicos e jurídicos. Revista de Ciências Empresariais da UNIPAR, v.10, n. 2, p. 241-267, 2009.

GUJARATI, D. N.; PORTER, C. D. Economia básica. Porto Alegre: Bookman, 2011.

ICA - THE INTERNATIONAL CO-OPERATIVE ALLIANCE. Identidade Cooperativa. Disponível em: https://www.ica.coop/es/cooperativas/identidad-alianza-cooperativa-

internacional?_ga=2.28844924.1784097686.1558791552-1533088085.1558791552. Acesso em: 12 de out. 2018.

INMET - INSTITUTO NACIONAL DE METEOROLOGIA. Precipitação total anual. s. d. Disponível em: http://www.inmet.gov.br/portal/index.php?r=clima/page\&page=desvioChuvaAnual. Acesso em 21 out. 2018.

IPEA - INSTITUTO DE PESQUISA ECONÔMICA APLICADA. Câmbio. Disponível em: http://www.ipeadata.gov.br/Default.aspx. Acesso em 21 out. 2018.

LONDERO, P. R.; BIALOSKORSKI NETO, S. Demonstração do valor adicionado como instrumento de evidenciação do impacto econômico e social das cooperativas agropecuárias. In: CONGRESSO ANPCONT, 10, 2016, Ribeirão Preto. Anais... São Paulo: 2016. 
LOPES, A. P. Análise de indicadores econômico-financeiros e sociais na gestão de cooperativas agropecuárias na região central do Estado do Rio Grande do Sul. 2009. 138 f. Dissertação (Mestrado em Extensão Rural) - Universidade Federal de Santa Maria. 2009.

MACIEL, A. P. B.; SEIBERT, R. M; SILVA, R. C. F.; WBATUBA, B. B. R.; SALLA, N. M. C. Governança em cooperativas: aplicação em uma cooperativa agropecuária. Revista de Administração Contemporânea, v. 22, n. 4, p. 600-619, 2018.

MARION, J. C. Análise das Demonstrações Contábeis, Contabilidade Empresarial. 2. ed. São Paulo: Atlas, 2002.

MARTINS, F. S.; LUCATO, W. C. Structural production factors' impact on the financial performance of agribusiness cooperatives in Brazil. International Journal of Operations \& Production Management, v. 38, n. 3, p. 6o6-635, 2018.

MARTINS, F. S.; LUCATO, W. C. Economic trade-offs amongst production diversification strategies in brasilizian South-eastern coffee cooperatives. Independent Journal of Management $\mathcal{E}$ Production, v. 5, n. 1, p. 83-105, 2014.

MENDONÇA, H. F. Transparência, condução da política monetária e metas para a inflação. Nova Economia - Belo Horizonte, v. 16, n. 1, p. 175-198, 2006.

NAKABASHI, L. Efeitos do câmbio e juros sobre as exportações da indústria brasileira. Revista de Economia Contemporânea, v.12, p. 433-461, 2008.

OCB - ORGANIZAÇÃO DAS COOPERATIVAS BRASILEIRAS. O que é cooperativismo. Disponível em: https://www.ocb.org.br/o-que-e-cooperativismo_Acesso em 30 jun. 2018.

OLIVEIRA, D. P. R. Manual de gestão das cooperativas: uma abordagem prática. 5. ed. São Paulo: Atlas, 2011.

PAULA, L.F.; PIRES, M. Crise e perspectiva para a economia brasileira. Estudos avançados, v. 31, n. 89, p. 125-144, 2017.

PIGNATA, F. A.; CARVALHO, D. O efeitos da crise econômica no Brasil em 2015. Revista Eletrônica Diálogos Acadêmicos, v. 9, n.2, p. 4-18, 2015.

PORTAL BIOSSISTEMAS BRASIL. A independência das chuvas na agricultura contemporânea. 2019. Disponível em: http://www.usp.br/portalbiossistemas/?p=8196. Acesso em 30 maio 2019.

SHAMSUDDIN, Z.; ISMAIL, A. G.; MAHMOOD, S.; ABDULLAH, M. F. Determinants of agricultural cooperative performance using financial ratio. International Journal of Business and Technopreneurship, v. 7, n. 3, p. 385-396, 2017.

SEBRAE - SERVIÇO BRASILEIRO DE APOIO ÀS MICRO E PEQUENAS EMPRESAS. Cooperativas. Brasília: 2014.

SILVA, J. P. Análise financeira das empresas. 12. ed. São Paulo: Atlas, 2013.

SNA - SOCIEDADE NACIONAL AGRÍCOLA. Agronegócio e a queda da inflação. 2017. Disponível em: https://www.sna.agr.br/agronegocio-e-a-queda-da-inflacao/. Acesso em 30 maio 2019.

SPOG - SECRETARIA DE PLANEJAMENTO, ORÇAMENTO E GESTÃO. Soja. Disponível em: https://atlassocioeconomico.rs.gov.br/soja. Acesso em 16 de abr 2018. 
SUCHMAN, M. C. Managing Legitimacy: Strategic and Institutional Approaches. Academy of Management review, v. 20, n. 3, p. 571-610, 1995.

VERGARA, S. C. Projetos e Relatórios de Pesquisa em Administração. 15. ed. São Paulo: Atlas, 2014.

WIKIPÉDIA. Crises econômicas. Disponível em: https://pt.wikipedia.org/wiki/Crise_econ\%C3\%B4mica. Acesso em 21 Out. 2018.

YAMAMOTO, R. K.; AKAMINE, C. T. Estudo dirigido de estatística descritiva. São Paulo: Érica, 2009. 